\title{
Response of Patient-Derived Non-Small Cell Lung Cancer Xenografts to Classical and Targeted Therapies Is Not Related to Multidrug Resistance Markers
}

\author{
Jana Rolff, ${ }^{1,2}$ Cornelia Dorn, ${ }^{2}$ Johannes Merk, ${ }^{3}$ and Iduna Fichtner ${ }^{2}$ \\ ${ }^{1}$ Experimental Pharmacology \& Oncology GmbH, Robert-Rössle-Street 10, 13122 Berlin, Germany \\ ${ }^{2}$ Experimental Pharmacology, Max-Delbrück-Center for Molecular Medicine, Robert-Rössle-Street 10, 13125 Berlin, Germany \\ ${ }^{3}$ Evangelische Lungenklinik, Lindenberger Weg 27, 13125 Berlin, Germany
}

Correspondence should be addressed to Iduna Fichtner, fichtner@mdc-berlin.de

Received 17 December 2008; Accepted 6 April 2009

Recommended by Daniel Chua

Tumor cells that are nonsensitive to anticancer drugs frequently have a multidrug resistant (MDR) phenotype. Many studies with cell lines and patient material have been done to investigate the impact of different resistance markers at protein and mRNA level in drug resistance but with contradictory outcome. In the present study, 26 well-characterised patient-derived non-small cell lung cancer xenografts were used. The known chemosensitivity to etoposide, carboplatin, gemcitabine, paclitaxel and erlotinib was compared to the protein and mRNA expression of BCRP, LRP, MDR1, and MRP1. Further, four of these xenografts were shortterm treated to analyse possible regulation mechanisms after therapeutic interventions. We found a borderline correlation between the bcrp mRNA expression and the response of xenografts to etoposide. All other constitutive mRNA and protein expression levels were not correlated to any drug response and were not significantly influenced by a short term treatment. The present results indicate that the expression levels of MDR proteins and mRNA investigated do not play an important role in the chemoresistance of NSCLC in the in vivo situation.

Copyright ( 2009 Jana Rolff et al. This is an open access article distributed under the Creative Commons Attribution License, which permits unrestricted use, distribution, and reproduction in any medium, provided the original work is properly cited.

\section{Introduction}

Lung cancer is still one of the most frequent cancers with about 1 million incidences worldwide each year. The 5-year survival rate is low with $10-15 \%$ compared to other cancers. For chemotherapeutic treatment the classical drugs like etoposide, gemcitabine, carbo- or cisplatin, vinorelbine, docetaxel, and paclitaxel are used. For some years also targeted therapies like tyrosine kinase inhibitors, like gefitinib, and erlotinib have been introduced into clinical trials. However, some patients seem to exhibit an intrinsic resistance or develop an acquired resistance under treatment. It was shown that active drug efflux transporters of the ATP binding cassette $(\mathrm{ABC})$ were involved that actively extrudes a range of structurally and functionally diverse drugs $[1,2]$. Three human $\mathrm{ABC}$ transporters are primarily associated with the multidrug resistance, namely, P-glycoprotein (P-gp, MDR1, $\mathrm{ABCB} 1)$, multidrug resistance protein 1 (MRP1, ABCC1), and breast cancer resistance protein (BCRP, ABCG2). They have broad and, to a certain extent, overlapping substrate specificities and are involved in transport processes for a variety of drugs used in chemotherapy. So it was shown that etoposide can be transported by MRP1 [3] and MDR1 that is also able to cause resistance to bulky amphipathic drugs, such as paclitaxel [1]. The lung cancer related protein (LRP) is associated with multidrug resistance because it was found to be overexpressed in an NSCLC cell line selected for doxorubicin resistance that did not express MDR1 [4]. Moreover, it was reported that erlotinib was a substrate for BCRP [5-7].

Most studies used only small numbers of lung cancer cell lines selected for resistance or patient material that was correlated with clinical features $[8,9]$. It was turned out that MRP1 played a major role in the intrinsic resistance. Further on, an activation of MDR1 expression during chemotherapy was suggested [10]. Additionally, it was shown that the 
response to Taxol-based chemotherapy was related to MDR1 but not LRP expression [11]. These partially conflicting data require further research.

Therefore we initiated a study in patient-derived NSCLC xenografts that were not selected for resistance and revealed a high coincidence with the original tumor [12]. We wanted to address the question if the level of resistance markers on mRNA or protein level is correlated with the response of xenografts to classical cytotoxic drugs (etoposide, carboplatin, gemcitabine, and paclitaxel) or targeted therapy (erlotinib).

\section{Methods}

2.1. Animal Experiments. 26 recently established NSCLC xenografts were used for this study (Table 1). The chemosensitivity was tested recently [12] so here described only shortly.

All animal experiments were done in accordance with the United Kingdom Co-ordinating Committee on Cancer Research regulations for the Welfare of Animals and of the German Animal Protection Law and approved by the local responsible authorities. The chemotherapeutic responsiveness of the passagable tumors was determined in male NMRI:nu/nu mice. One tumor fragment each was transplanted subcutaneously to the mice. At palpable tumor size $\left(50-100 \mathrm{~mm}^{3}\right)$ mice each was randomised to treatment and control groups The following drugs and treatment modalities were used: etoposide (Vepesid, BristolMeyers Squibb) $10 \mathrm{mg} / \mathrm{kg} / \mathrm{d}$, qd 1-5, i.p.; carboplatin (Mayne Pharma Deutschland GmbH) $75 \mathrm{mg} / \mathrm{kg} / \mathrm{d}$, qd 1 and 8, i.p.; gemcitabine (Gemzar, Lilly Deutschland) $60-80 \mathrm{mg} / \mathrm{kg} / \mathrm{d}$, qd 1, 4, 7, 10, i.p.; paclitaxel (Taxol, Sigma) $12.5 \mathrm{mg} / \mathrm{kg} / \mathrm{d}$, qd 15, i.v.; erlotinib (Tarceva, Hoffmann-LaRoche) $50 \mathrm{mg} / \mathrm{kg} / \mathrm{d}$, qd 1-5, 8-12, orally. Doses and schedules were chosen according to previous experience in animal experiments and represent the maximum tolerated or efficient doses. The injection volume was $0.2 \mathrm{~mL} / 20 \mathrm{~g}$ body weight.

In this study, the four models 7406, 7433, 7700, and 7747 were selected because of their differential chemosensitivity (Table 1). 7406 was choosen because it was the only model that not responded to carboplatin and gemcitabine at once but responded to erlotinib. The other models were randomly selected but should represent the high response rates of all tumors to carboplatin and paclitaxel (models 7433, 7747) and gemcitabine and paclitaxel (7700). At the same time they should not respond to more than two drugs to keep the factors of influence low. For the short-term treated xenografts three mice each were randomised to treatment and control groups. The drug doses and application mode were the same as described above except that the treatment was carried out for three days. 24 hours after the last treatment the mice were sacrificed, tumors were snap frozen and stored at $-80^{\circ} \mathrm{C}$. Total RNA and protein were isolated for the analysis.

2.2. Real-Time PCR. RNA was isolated with RNA Isolation Kit (Qiagen) according to the manufacturers instructions. Total RNA was reversely transcribed using TaqMan Reverse
Transcription Reagents (Applied Biosystems (AB)) and TaqMan quantitative real-time PCR performed using cDNA corresponding to $40 \mathrm{ng}$ RNA per reaction. Gene and species specific primers for bcrp, $\operatorname{lrp}, m d r 1, m r p 1$, and $\beta$-actin and TaqMan Fast Mastermix (AB) were used according to the manufacturers instructions and amplifications carried out on the StepOne Plus Real-Time PCR system (AB) with 45 cycles. Each sample was done in two replicates. Normalised $\Delta \mathrm{C}_{\mathrm{T}}$ values were obtained by subtracting the $\beta$-actin $\mathrm{C}_{\mathrm{T}}$ from the gene of interest $\mathrm{C}_{\mathrm{T}}$. Tumor samples have been done 2fold and as positive controls MDA-MB-231/BCRP, A549 and MT3/ADR were used.

2.3. Immunoblotting. Lysates for immunoblotting were prepared by adding lysis buffer $(150 \mathrm{mM} \mathrm{NaCl}, 20 \mathrm{mM}$ Tris, $1 \%$ Triton $\mathrm{X}-100,0,5 \%$ sodiumdesoxycholate, $0.5 \%$ SDS, $2 \mathrm{mM}$ EDTA, $2.5 \mathrm{mM}$ sodium pyrophosphate, $1 \mathrm{mM} \beta$ glycerophosphat; $\mathrm{pH}$ 7.7) containing protease and phosphatase inhibitors (Sigma-Aldrich) to the tumor tissue. The protein concentration was determined using BioRad Protein Assay (BioRad Laboratories GmbH). Tumor lysates $(20 \mu \mathrm{g})$ were separated on $8 \%$ SDS-page polyacrylamide gels and transferred to nitrocellulose membranes. Membranes were blocked and incubated with the primary antibodies (BCRP, 801-029-C125, Alexis; LRP, 610512, BD) overnight at $4^{\circ} \mathrm{C}$. The secondary antibody (115-035-003, Jackson Immuno Research) was conjugated with horseradish peroxidase. Protein bands were visualized using the enhanced chemiluminescence detection system (GE Health Amersham Life Science Inc). To verify equal protein loading, the blots were stripped and reprobed for $\beta$-actin (Sigma). MDA-MB231/BCRP and A549 were used as positive controls.

2.4. FACS Analyses. One piece of each tumour was crudely cut into smaller pieces and further separated with a cell strainer till a cell suspension was obtained. Approximately $1 \times 10^{6}$ cells were used for analyses. After blocking with goat serum, cells were incubated with the primary antibody (MDR1 557001, BD; MRP1, 557594, BD) and secondary Cy3-conjugated goat anti mouse antibody (115-165-146, Jackson Immuno Research). As positive control MT3/ADR breast cancer cells were used.

2.5. Statistical Analyses. Analyses of the mRNA or protein expression levels in comparison with the response to treatment have been done. The correlation according to Spearman and the $P$-values was calculated with the SPSS software. The correlation coefficient $(r)$ could range between 0 (no correlation) and 1 (strong correlation).

\section{Results}

3.1. Constitutive Protein Expression in the 26 NSCLC Models. BCRP protein was detected in 18/26 xenografts with a weak to strong intensity. LRP could be found in 24 xenografts with 
TABLE 1: Chemosensitivity testing, constitutive protein, and mRNA expression of BCRP, LRP, MDR1, and MRP1 in 26 xenografts and the positive controls. Response: - negativ: $100-50 \% \mathrm{~T} / \mathrm{C},+35-50 \% \mathrm{~T} / \mathrm{C},++21-35 \% \mathrm{~T} / \mathrm{C},+++6-20 \% \mathrm{~T} / \mathrm{C},++++0-5 \% \mathrm{~T} / \mathrm{C}$, tox-toxic, n.t.-not tested; protein expression: - not detected, + weak, ++ medium, +++ strong expression; \% of positive cells; mRNA expression: normalised $\Delta \mathrm{C}_{\mathrm{T}}$ values; etp—etoposide, carpl—carboplatin, gem—gemcitabine, paltx—paclitaxel, erlo—erlotinib.

\begin{tabular}{|c|c|c|c|c|c|c|c|c|c|c|c|c|c|}
\hline \multirow[b]{3}{*}{$\mathrm{LuCa}$} & \multirow{2}{*}{\multicolumn{5}{|c|}{ Chemosensitivity }} & \multicolumn{8}{|c|}{ Before treatment } \\
\hline & & & & & & \multicolumn{4}{|c|}{ Protein expression } & \multicolumn{4}{|c|}{ mRNA expression } \\
\hline & etp & Carpl & gem & paltx & erlo & BCRP & LRP & MDR1 [\%] & MRP1 [\%] & bcrp & lrp & mdr1 & mrpl \\
\hline 7064 & ++ & - & - & ++ & ++ & - & + & 15.4 & 13.8 & 12.19 & 8.01 & 17.54 & 7.10 \\
\hline 7126 & - & - & +++ & - & ++ & +++ & + & 15.3 & 18.2 & 4.17 & 5.04 & 18.18 & 3.45 \\
\hline 7166 & ++ & ++ & + & - & - & - & +++ & 13.7 & 13.8 & 15.46 & 6.45 & 0 & 7.16 \\
\hline 7177 & - & ++ & +++ & - & ++ & - & ++ & 14.5 & 29.5 & 10.42 & 5.33 & 16.97 & 2.02 \\
\hline 7187 & - & ++ & +++ & - & - & - & ++ & 15.4 & 18.3 & 8.13 & 6.90 & 0 & 7.55 \\
\hline 7198 & - & + & + & + & - & +++ & ++ & 27.2 & 20.9 & 10.13 & 6.18 & 21.24 & 6.25 \\
\hline 7298 & + & + & ++ & ++ & - & - & ++ & 14.4 & 13.1 & 15.03 & 5.79 & 17.19 & 6.33 \\
\hline 7336 & - & $(+)$ & ++ & +++ & - & +++ & + & 13.3 & 13.6 & 8.08 & 6.68 & 0 & 7.02 \\
\hline 7343 & - & +++ & +++ & ++ & - & + & + & 20.8 & 24.1 & 8.34 & 5.85 & 0 & 5.23 \\
\hline 7387 & - & - & +++ & ++++ & - & ++ & ++ & 15.4 & 29.9 & 6.15 & 7.64 & 10.90 & 7.57 \\
\hline 7406 & + & + & +++ & +++ & - & +++ & + & 29.4 & 22.4 & 14.87 & 7.61 & 14.97 & 8.10 \\
\hline 7414 & - & ++ & +++ & +++ & + & - & ++ & 17.9 & 15.6 & 7.13 & 5.69 & 0 & 6.21 \\
\hline 7433 & - & +++ & - & ++++ & - & - & +++ & 18.8 & 22.1 & 6.99 & 5.68 & 17.20 & 3.73 \\
\hline 7462 & - & + & ++++ & +++ & ++ & + & - & 39.8 & 31.3 & 7.65 & 5.24 & 9.36 & 7.78 \\
\hline 7466 & - & - & ++++ & ++++ & ++ & + & ++ & 15.5 & 18.6 & 8.62 & 7.56 & 22.43 & 8.65 \\
\hline 7506 & - & ++++ & $(+)$ & +++ & - & + & + & 65.8 & 19.0 & 10.96 & 7.07 & 15.94 & 6.98 \\
\hline 7530 & ++++ & - & tox & +++ & - & +++ & + & 20.1 & 16.1 & 14.27 & 8.24 & 14.35 & 8.01 \\
\hline 7558 & - & ++++ & +++ & - & - & +++ & ++ & 24.0 & 25.3 & 15.90 & 6.26 & 18.64 & 6.38 \\
\hline 7612 & - & ++++ & - & +++ & - & - & + & 17.7 & 15.5 & 11.09 & 5.89 & 16.98 & 6.04 \\
\hline 7668 & - & +++ & tox & ++++ & - & +++ & - & 17.2 & 24.8 & 7.55 & 6.12 & 13.42 & 6.17 \\
\hline 7700 & - & - & ++++ & ++ & - & ++ & +++ & 18.1 & 13.9 & 15.81 & 6.01 & 17.32 & 7.96 \\
\hline 7747 & - & ++ & - & ++ & - & + & ++ & 62.0 & 15.0 & 15.19 & 4.82 & 18.29 & 6.26 \\
\hline 7766 & - & +++ & + & ++ & - & + & + & 33.1 & 18.0 & 6.72 & 5.18 & 17.88 & 4.14 \\
\hline 7860 & + & - & ++ & +++ & - & + & ++ & 20.6 & 22.4 & 11.16 & 4.96 & 16.41 & 5.47 \\
\hline 7913 & - & + & $(+)$ & +++ & - & + & ++ & 14.0 & n.t. & 13.50 & 5.64 & 18.47 & 6.17 \\
\hline 7915 & n.t & n.t & n.t & n.t & - & + & ++ & 16.0 & 13.8 & 14.27 & 8.49 & 16.21 & 6.87 \\
\hline MDA-MB-231/BCRP & & & & & & & & & & 2.51 & & & \\
\hline A549 & & & & & & & & & & & 9.97 & & 5.54 \\
\hline MT3/ADR & & & & & & & & & & & & 3.49 & \\
\hline
\end{tabular}

different expression levels. Two NSCLC 7462 and 7668 lacked expression of LRP. MDR1 and MRP1 proteins were detected in all xenografts with an almost equal expression level (see Table 1).

3.2. Constitutive mRNA Expression in the 26 NSCLC Models. $B c r p$ was expressed in the xenografts in a $\Delta \mathrm{C}_{\mathrm{T}}$ range between 4 (7126) and 16 (7558). Mdr1 was detected in all xenografts except in five $(7166,7187,7336,7343$, and 7414). The highest expression with a $\Delta \mathrm{C}_{\mathrm{T}}$ value of 9 was found in xenograft 7462 , the lowest level with a $\Delta \mathrm{C}_{\mathrm{T}} 22$ in 7466. Nearly half of the other xenografts (13) had $\Delta \mathrm{C}_{\mathrm{T}}$ value in a dose range between 15 and 19 . The expression of $m r p 1$ varied from $\Delta \mathrm{C}_{\mathrm{T}}$ values of 2 to 8 . In 13 xenografts a $\Delta C_{T}$ value between 6 and 7 was found. The $\operatorname{lrp}$ levels ranged in all xenografts between $\Delta \mathrm{C}_{\mathrm{T}} 5$ and 8 , hence presenting a relatively homogeneous expression. Bcrp and $m d r 1$ had the most heterogeneous
mRNA expression pattern, and the overall expression level oflrp and $m r p 1$ was higher than that of $b c r p$ and $m d r 1$ in the 26 xenografts.

A borderline correlation between chemosensitivity and mRNA expression was found in the comparison of etoposide and $b c r p(r=0.490)$. All 6 xenografts sensitive to etoposide showed a lower bcrp expression $\Delta \mathrm{C}_{\mathrm{T}} 13,8( \pm 1.6)$ whereas the resistant tumors had a mean $\Delta \mathrm{C}_{\mathrm{T}}$ of $9,6( \pm 3.3)$. The comparison of the $l r p, m d r 1$, and $m r p 1$ expression with the chemosensitivity towards the different drugs revealed no further correlations.

3.3. mRNA Expression in the Xenografts after Short-Term Treatment. RNA was isolated after short-term treatment of the xenografts $7406,7433,7700$, and 7747.

In all four xenografts the mRNA of $b c r p, \operatorname{lr} p, m d r 1$, and mrp1 could be detected. For one and the same xenograft 

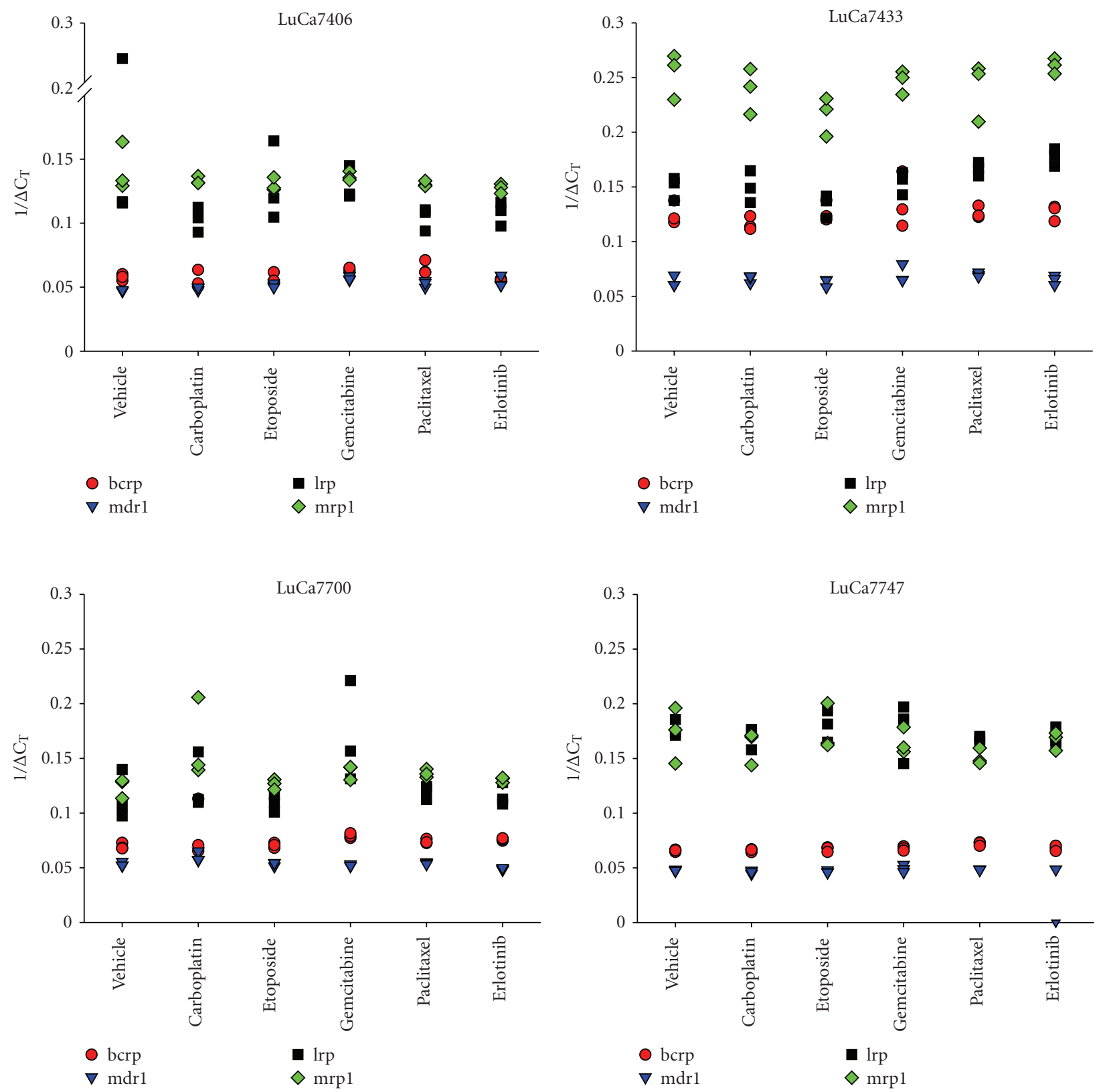

FiguRe 1: mRNA expression of $b c r p$, $\operatorname{lrp}, m d r 1$, and $m r p 1$ after short-term treatment in xenografts 7406, 7433, 7700, and 7747. Treatment was performed for three consecutive days. Three tumor samples per group were taken 24 hours after last treatment.

the mRNA expression was independent of the treatment (Figure 1). The $\Delta \mathrm{C}_{\mathrm{T}}$ values differed in a range of two. No significant up- or down-regulations of the mRNA after treatment with etoposide, carboplatin, gemcitabine, paclitaxel, and erlotinib could be observed.

3.4. Protein Expression in the Xenografts after Short-Term Treatment. The BCRP and MRP1 proteins were detected at a medium or weak expression level, whereas LRP had a strong expression in the all xenografts. MDR1 protein could be found in all xenografts. All groups of one model showed an equal expression level of BCRP, LRP, and MDR. There was no regulation detectable after treatment in each NSCLC xenograft (data not shown).

\section{Discussion}

A large number of studies dealing with questions of intrinsic or acquired drug resistance used cell line-based approaches. Hence, it was shown that amplification and overexpression of $B C R P$ emerged as the dominant resistance mechanism in MDR1 and MRP1-deficient mouse fibroblast and kidney cell lines that were selected for resistance to etoposide [13]. In the present study, comparing etoposide response to bcrp mRNA expression the tendency was shown that all sensitive 
xenografts had a lower expression level than the nonsensitive tumors. Similar correlations could not be found at the protein level. Recently, it was demonstrated that erlotinib was a substrate for BCRP and MDR1 which may explain the resistance seen in the clinics [6]. In our study, we did not observe any correlation between response and BCRP or MDR1 expression neither at protein nor at mRNA level.

Various studies showed that the expression of $L R P$ closely reflected the chemoresistance profile of many tumor cell lines and clinical cancer [4, 14-17]. Elevated LRP levels were observed in cell lines resistant to cytotoxic agents like doxorubicin, etoposide, vincristine, and cisplatin [4, 18, 19]. In nonselected NSCLC cells LRP protein and mRNA expression levels correlated with resistance to cisplatin [20]. However, in the present study, no correlation was observed regarding resistance to etoposide, carboplatin or other drugs and the expression of LRP. In other studies, likewise, no correlation with relevant clinical or clinicopathological parameters could be demonstrated $[21,22]$. Anyway, in non-small cell and small cell lung cancer patients, the expression was different with the highest expression found in chemoresistant NSCLC [21].

In the present study, a relation of MRP1 expression neither to cisplatin nor to etoposide response was seen. In contrast, other authors reported that MRP1 expression was correlated with lower chemosensitivity to etoposide, but not to cisplatin in lung cancer cell lines and patients $[8,23,24]$. NSCLC patients were found to exhibit mostly low, but occasionally high MRP1 mRNA expression levels [25]. Another study indicated that either one, or both, MDR1 or MRP1 was frequently expressed in NSCLC, and expression of $m r p 1$ was found to be predominant over $m d r 1$ at the mRNA level [26]. This could be confirmed in the present study as it detected almost equal mRNA expression levels among the xenografts. In general, the $m r p 1$ level was higher than that of the $m d r 1$.

For MDR1 expression also contradictory literature exists. Some concluded that Taxol-based chemotherapy response of NSCLC patients was related to MDR1 but not LRP expression [11] while others suggested that MDR proteins (LRP, MDR1, and MRP1) may not play an important role in the chemoresistance and drug efflux of NSCLC cells [9]. We were not able to demonstrate any correlation between the chemosensitivity and the expression of MDR. Even after short-term treatment no remarkable changes of mRNA or protein could be observed.

One reason for the different results described in literature and found by us could be the model system used. While we used patient-derived xenografts that were not selected for any drug resistance, many other studies included cell lines passaged over years or selected for resistance under high drug concentrations. The in vivo situation is different because the drug availability and exact "in-tumor" concentration are not exactly known. However, the response rates of xenografts were similar to those observed in human Phase II studies with the same agents $[12,27]$. Patient-derived xenografts allow the detailed investigation of therapy related markers and their dynamic regulation in a well-standardized and clinically related way.

Moreover, the multidrug resistance is regarded to be a multifactorial phenomenon in which more than the markers studied in the present study could be involved.

\section{Acknowledgments}

The authors gratefully thank Diana Anders and Monika Becker for excellent technical support in animal experiments. Michael Becker is acknowledged for critical reading of the manuscript.

\section{References}

[1] P. Borst and R. O. Elferink, "Mammalian ABC transporters in health and disease," Annual Review of Biochemistry, vol. 71, pp. 537-592, 2002.

[2] A. H. Schinkel and J. W. Jonker, "Mammalian drug efflux transporters of the ATP binding cassette (ABC) family: an overview," Advanced Drug Delivery Reviews, vol. 55, no. 1, pp. 3-29, 2003.

[3] É. Bakos and L. Homolya, "Portrait of multifaceted transporter, the multidrug resistance-associated protein 1 (MRP1/ABCC1)," Pflügers Archiv European Journal of Physiology, vol. 453, no. 5, pp. 621-641, 2007.

[4] R. J. Scheper, H. J. Broxterman, G. L. Scheffer, et al., "Overexpression of a $M_{\mathrm{r}} \quad 110,000$ vesicular protein in non-P-glycoprotein-mediated multidrug resistance," Cancer Research, vol. 53, no. 7, pp. 1475-1479, 1993.

[5] J. Li, G. Cusatis, J. Brahmer, et al., "Association of variant ABCG2 and the pharmacokinetics of epidermal growth factor receptor tyrosine kinase inhibitors in cancer patients," Cancer Biology and Therapy, vol. 6, no. 3, pp. 432-438, 2007.

[6] S. Marchetti, N. A. de Vries, T. Buckle, et al., "Effect of the ATP-binding cassette drug transporters ABCB1, ABCG2, and ABCC2 on erlotinib hydrochloride (Tarceva) disposition in in vitro and in vivo pharmacokinetic studies employing $\mathrm{Bcrp}^{-/-} / \mathrm{Mdrla} / 1 \mathrm{~b}^{-/-}$(triple-knockout) and wild-type mice," Molecular Cancer Therapeutics, vol. 7, no. 8, pp. 22802287, 2008.

[7] C. Özvegy-Laczka, J. Cserepes, N. B. Elkind, and B. Sarkadi, "Tyrosine kinase inhibitor resistance in cancer: role of $\mathrm{ABC}$ multidrug transporters," Drug Resistance Updates, vol. 18, no. 1, pp. 15-26, 2005.

[8] W. Berger, L. Elbling, E. Hauptmann, and M. Micksche, "Expression of the multidrug resistance-associated protein (MRP) and chemoresistance of human non-small-cell lung cancer cells," International Journal of Cancer, vol. 73, no. 1, pp. 84-93, 1997.

[9] K. Ikuta, K. Takemura, K. Sasaki, et al., "Expression of multidrug resistance proteins and accumulation of cisplatin in human non-small cell lung cancer cells," Biological \& Pharmaceutical Bulletin, vol. 28, no. 4, pp. 707-712, 2005.

[10] W. Berger, U. Setinek, P. Hollaus, et al., "Multidrug resistance markers P-glycoprotein, multidrug resistance protein 1, and lung resistance protein in non-small cell lung cancer: prognostic implications," Journal of Cancer Research and Clinical Oncology, vol. 131, no. 6, pp. 355-363, 2005.

[11] J.-F. Chiou, J.-A. Liang, W.-H. Hsu, J.-J. Wang, S.-T. Ho, and A. Kao, "Comparing the relationship of taxol-based chemotherapy response with P-glycoprotein and lung resistance-related 
protein expression in non-small cell lung cancer," Lung, vol. 181, no. 5, pp. 267-273, 2003.

[12] I. Fichtner, J. Rolff, R. Soong, et al., "Establishment of patientderived non-small cell lung cancer xenografts as models for the identification of predictive biomarkers," Clinical Cancer Research, vol. 14, no. 20, pp. 6456-6468, 2008.

[13] J. D. Allen, S. C. van Dort, M. Buitelaar, O. van Tellingen, and A. H. Schinkel, "Mouse breast cancer resistance protein (Bcrp1/Abcg2) mediates etoposide resistance and transport, but etoposide oral availability is limited primarily by Pglycoprotein," Cancer Research, vol. 63, no. 6, pp. 1339-1344, 2003.

[14] M. A. Izquierdo, G. L. Scheffer, M. J. Flens, R. H. Shoemaker, L. H. Rome, and R. J. Scheper, "Relationship of LRP-human major vault protein to in vitro and clinical resistance to anticancer drugs," Cytotechnology, vol. 19, no. 3, pp. 191-197, 1996.

[15] V. A. Kickhoefer, K. S. Rajavel, G. L. Scheffer, W. S. Dalton, R. J. Scheper, and L. H. Rome, "Vaults are up-regulated in multidrug-resistant cancer cell lines," The Journal of Biological Chemistry, vol. 273, no. 15, pp. 8971-8974, 1998.

[16] A. B. Schroeijers, A. C. Siva, G. L. Scheffer, et al., "The $M_{\mathrm{r}} 193,000$ vault protein is up-regulated in multidrugresistant cancer cell lines," Cancer Research, vol. 60, no. 4, pp. 1104-1110, 2000.

[17] A. C. Siva, S. Raval-Fernandes, A. G. Stephen, et al., "Upregulation of vaults may be necessary but not sufficient for multidrug resistance," International Journal of Cancer, vol. 92, no. 2, pp. 195-202, 2001.

[18] C. M. Laurençot, G. L. Scheffer, R. J. Scheper, and R. H. Shoemaker, "Increased LRP mRNA expression is associated with the MDR phenotype in intrinsically resistant human cancer cell lines," International Journal of Cancer, vol. 72, no. 6, pp. 1021-1026, 1997.

[19] B. Wyler, Y. Shao, E. Schneider, et al., "Intermittent exposure to doxorubicin in vitro selects for multifactorial non-Pglycoprotein-associated multidrug resistance in RPMI 8226 human myeloma cells," British Journal of Haematology, vol. 97, no. 1, pp. 65-75, 1997.

[20] W. Berger, L. Elbling, and M. Micksche, "Expression of the major vault protein LRP in human non-small-cell lung cancer cells: activation by short-term exposure to antineoplastic drugs," International Journal of Cancer, vol. 88, no. 2, pp. 293 $300,2000$.

[21] A.-M. C. Dingemans, J. van Ark-Otte, P. van der Valk, et al., "Expression of the human major vault protein LRP in human lung cancer samples and normal lung tissues," Annals of Oncology, vol. 7, no. 6, pp. 625-630, 1996.

[22] M. Volm, J. Mattern, and R. Koomagi, "Expression of lung resistance-related protein (LRP) in non-small cell lung carcinomas of smokers and non-smokers and its predictive value for doxorubicin resistance," Anticancer Drugs, vol. 8, no. 10, pp. 931-936, 1997.

[23] G. Giaccone, J. van Ark-Otte, G. J. Rubio, et al., "MRP is frequently expressed in human lung-cancer cell lines, in nonsmall-cell lung cancer and in normal lungs," International Journal of Cancer, vol. 66, no. 6, pp. 760-767, 1996.

[24] M. Filipits, V. Haddad, K. Schmid, et al., "Multidrug resistance proteins do not predict benefit of adjuvant chemotherapy in patients with completely resected non-small cell lung cancer: International Adjuvant Lung Cancer Trial Biologic Program,” Clinical Cancer Research, vol. 13, no. 13, pp. 3892-3898, 2007.

[25] K. Nooter, A. M. Westerman, M. J. Flens, et al., "Expression of the multidrug resistance-associated protein (MRP) gene in human cancers," Clinical Cancer Research, vol. 1, no. 11, pp. 1301-1310, 1995.

[26] S. Roy, E. Kenny, S. Kennedy, et al., "MDR1/P-glycoprotein and MRP-1 mRNA and protein expression in non-small cell lung cancer," Anticancer Research, vol. 27, no. 3A, pp. 13251330, 2007.

[27] R. Perez-Soler, B. Kemp, Q. P. Wu, et al., "Response and determinants of sensitivity to paclitaxel in human non-small cell lung cancer tumors heterotransplanted in nude mice," Clinical Cancer Research, vol. 6, no. 12, pp. 4932-4938, 2000. 


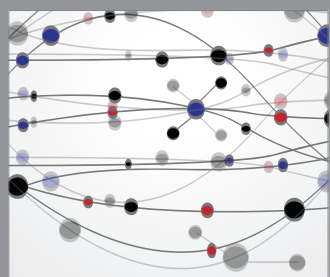

The Scientific World Journal
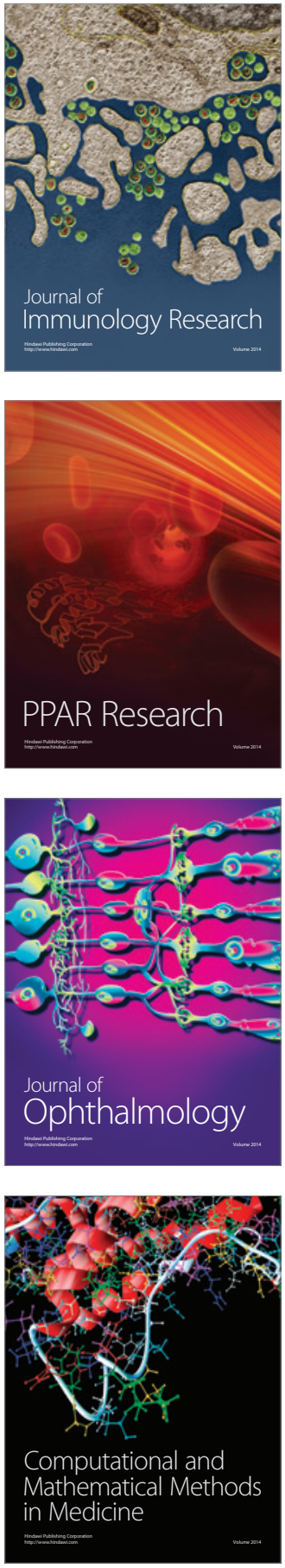

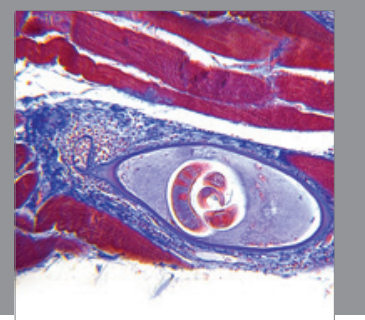

Gastroenterology

Research and Practice
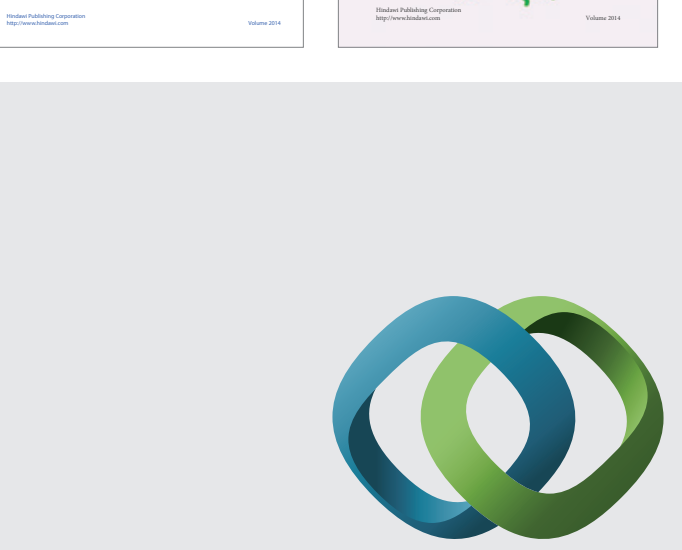

\section{Hindawi}

Submit your manuscripts at

http://www.hindawi.com
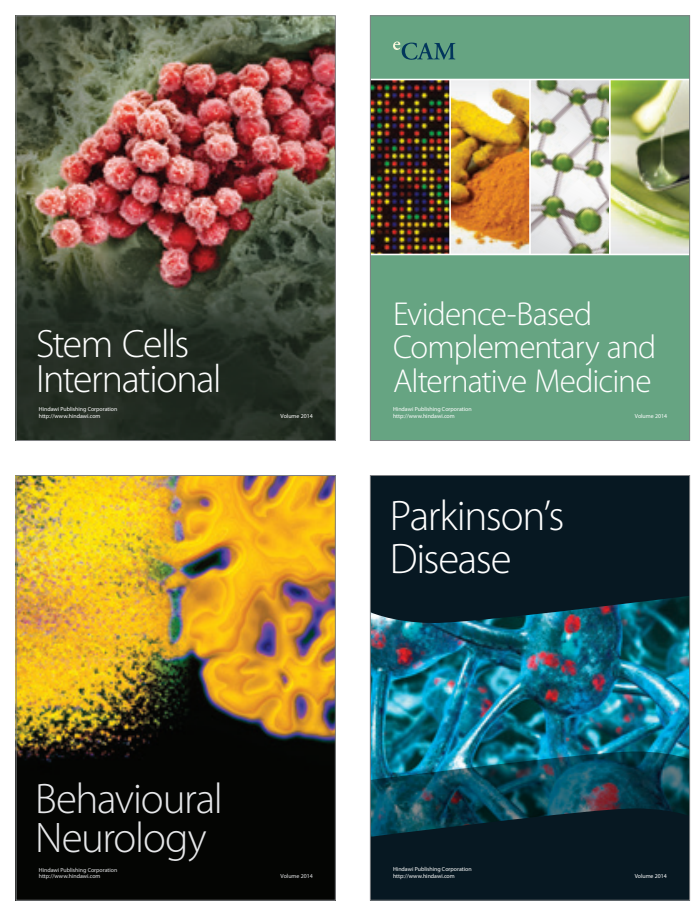

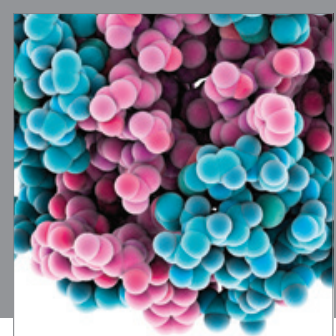

Journal of
Diabetes Research

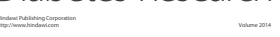

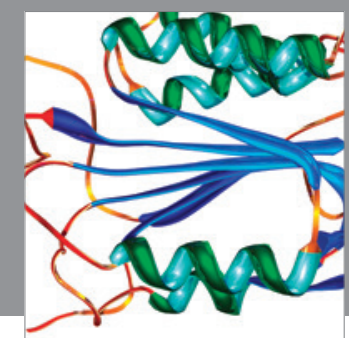

Disease Markers
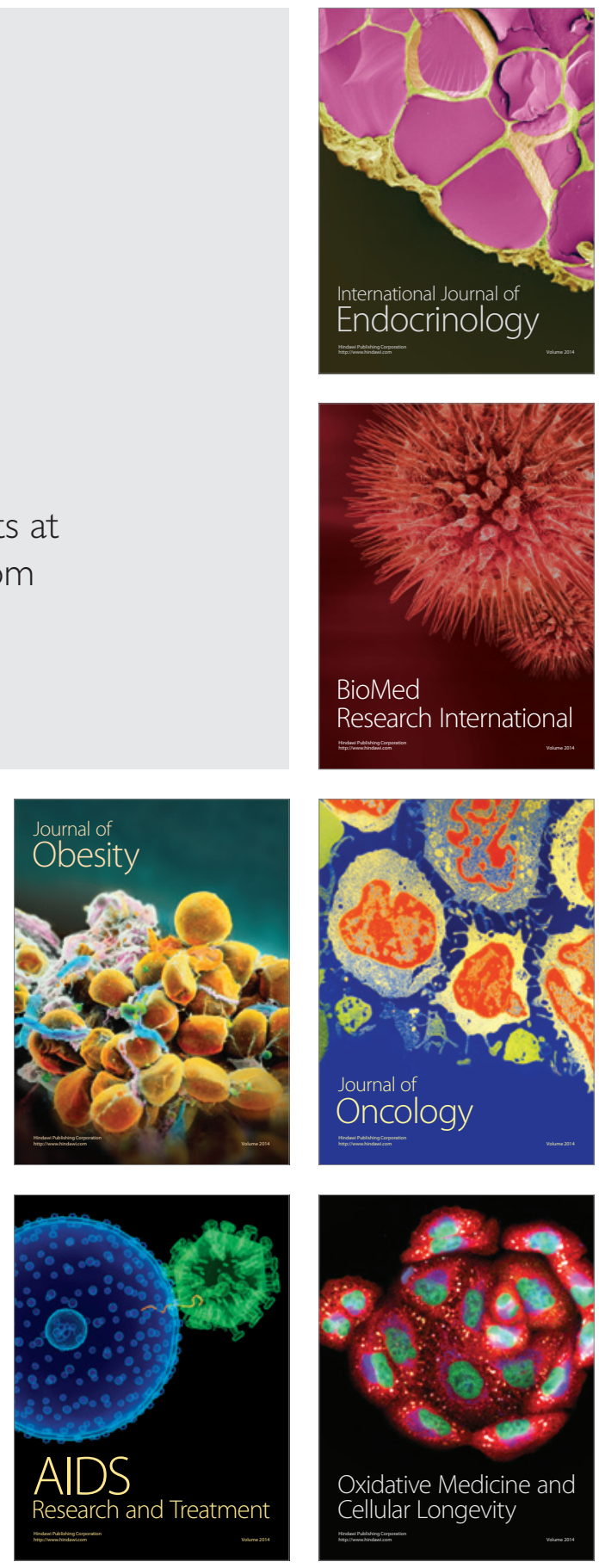